\title{
A PROSPECTIVE OBSERVATIONAL STUDY ON ADVERSE CUTANEOUS DRUG REACTIONS IN A TERTIARY CARE CENTRE IN SOUTH INDIA
}

\author{
Suganthy Valavan', Karpagam Baliah², Parimalam Kumar ${ }^{3}$ \\ ${ }^{1}$ Assistant Professor, Department of Dermatology, Government Villupuram Medical College, Villupuram, Tamilnadu. \\ ${ }^{2}$ Assistant Professor, Department of Dermatology, Government Villupuram Medical College, Villupuram, Tamilnadu. \\ ${ }_{3}^{3}$ Associate Professor, Department of Dermatology, Government Villupuram Medical College, Villupuram, Tamilnadu.
}

\section{ABSTRACT}

\section{BACKGROUND}

An adverse drug reaction (ADR) is defined as any noxious, unintended and undesired effect of a drug, which occurs at doses used in humans for diagnosis, prophylaxis or therapy. ${ }^{1}$ Cutaneous adverse drug reactions are one of the most common types of ADRs. The incidence of cutaneous adverse drug reactions varies from $1-3 \%$ in developed countries to 2 - $5 \%$ in developing countries. ${ }^{2}$

Aims and Objectives: To determine the prevalence of cutaneous adverse drug reactions in our hospital and to identify the clinical patterns of the drug eruptions and the common drugs implicated among our patients.

\section{MATERIALS AND METHODS}

The study was done over a period of two years. Hundred patients presenting with cutaneous drug reactions were registered and analysed. The demographic details were recorded, and a thorough clinical examination was done.

\section{RESULTS}

Out of the hundred patients enrolled, 45 were males and 48 were females. There were 2 male children and 5 female children. Most of the patients were in the age group of 21 - 30 and 31 - 40 years, 21 each. Antibiotics were the commonest (30 patients) group of drugs implicated followed by analgesics (29 patients). Fixed drug eruptions were the commonest reaction pattern noticed (32 patients) followed by urticaria and angioedema (25 patients). Females were more commonly affected than males.

\section{CONCLUSION}

The clinical pattern of the cutaneous adverse drug reactions is varied in this locality, the knowledge of which is essential for the clinicians.

\section{KEY WORDS}

Cutaneous Adverse Drug Reactions, Clinical Patterns, Demographic Profile.

HOW TO CITE THIS ARTICLE: Valavan S, Baliah K, Kumar P. A prospective observational study on adverse cutaneous drug reactions in a tertiary care centre in South India. J. Evolution Med. Dent. Sci. 2018;7(20):2453-2455, D0I: $10.14260 /$ jemds/2018/552

\section{BACKGROUND}

An adverse drug reaction (ADR) is defined as any noxious, unintended and undesired effect of a drug, which occurs at doses used in humans for diagnosis, prophylaxis or therapy. ${ }^{1}$ Cutaneous adverse drug reactions are one of the most common types of ADRs. The incidence of cutaneous adverse drug reactions varies from 1-3 in developed countries to 2$5 \%$ in developing countries. ${ }^{2}$ Majority of CADRs are mild and self-limiting. Severe life-threatening reactions are StevensJohnson Syndrome (SJS), Toxic Epidermal Necrolysis (TEN) and Drug reaction with Eosinophilia and Systemic Symptoms (DRESS). They may occur with prescribed medications, OTC drugs (or) native medicines.

'Financial or Other Competing Interest': None.

Submission 06-04-2018, Peer Review 29-04-2018,

Acceptance 07-05-2018, Published 14-05-2018.

Corresponding Author:

Dr. Karpagam Baliah,

Assistant Professor,

Department of Dermatology,

Government Villupuram Medical College,

Villupuram

Tamilnadu.

E-mail:drbkarpagam@gmail.com

DOI: $10.14260 /$ jemds $/ 2018 / 552$

\section{(c) (i) (8) $\Theta$}

\section{Aims and Objectives}

To determine the prevalence of cutaneous adverse drug reactions in our hospital and to identify the clinical patterns of the drug eruptions and the common drugs implicated among our patients.

\section{MATERIALS AND METHODS}

It is a prospective observational study, conducted for two years. Hundred patients presenting with drug reactions in our dermatology outpatient were registered and evaluated. A thorough history regarding the evolution of lesions, drug intake, the indication for which it was taken and improvement on cessation of the drug intake were taken. A general physical examination was also done. The various drugs implicated, and the types of clinical reactions were categorised. The results were tabulated and analysed.

\section{RESULTS}

The total number of patients with adverse drug reaction was 100 , out of which 45 were males and 48 were females with 2 male children and 5 female children respectively. The youngest patient was a 4-year-old girl, who developed a morbilliform rash following cotrimoxazole intake for respiratory infection. The oldest patient was an 83-year-old male, who developed $\mathrm{FDE}^{1}$ following intake of unknown drug for urinary tract infection. Most of the patients were recorded 
in the age group of $21-30$ and $31-40$, which was 21 each (Table 1).

Antibiotics were the commonest group of drugs implicated in the drug reactions (30 patients) followed by Analgesics (29), Anti-epileptics (6), miscellaneous drugs (4) and native medicines (3). 28 patients were not aware of the offending drug. Cotrimoxazole was the commonest antibiotic implicated in drug reaction.

FDE was the commonest reaction pattern noticed $(32$ patients) followed by urticaria and angioedema (25), maculopapular rash (15), SJS (9), TEN (7), Bullous eruptions (4), Pruritus (3), EMF (3), lichenoid dermatitis (1) and PR (1). FDE was the most commonly induced by cotrimoxazole.

Pain was the most common indication for usage of the offending drug (37\%). Respiratory tract infection (18\%) was the next common, closely followed by fever (16\%). Diarrhoea was the indication in $11 \%$ of the patients. Dermatological causes were recorded in $5 \%$ and another $5 \%$ patients gave miscellaneous indications for the use of the incriminated drug.

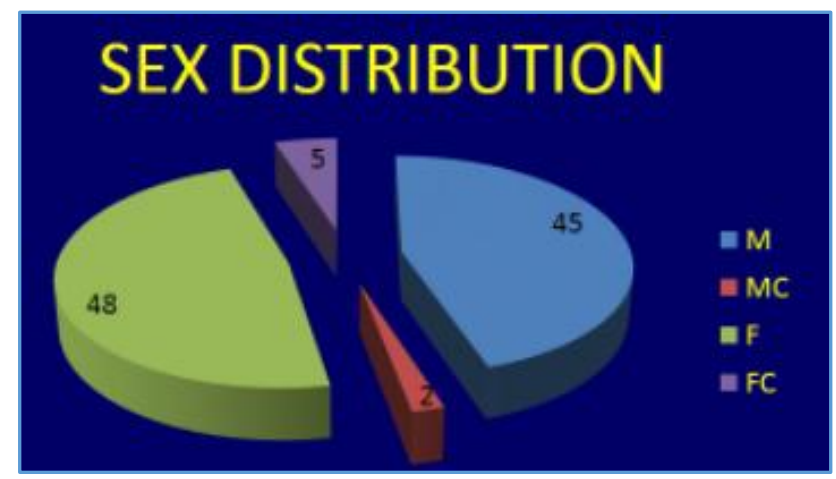

Figure 1

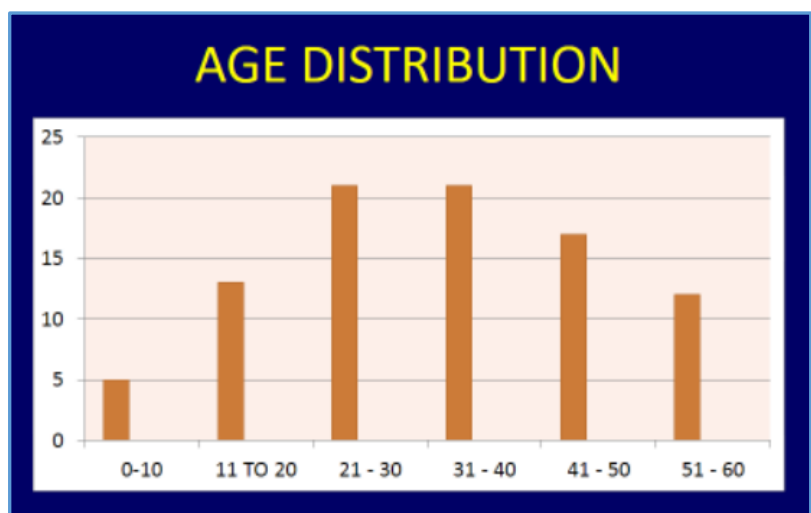

Figure 2

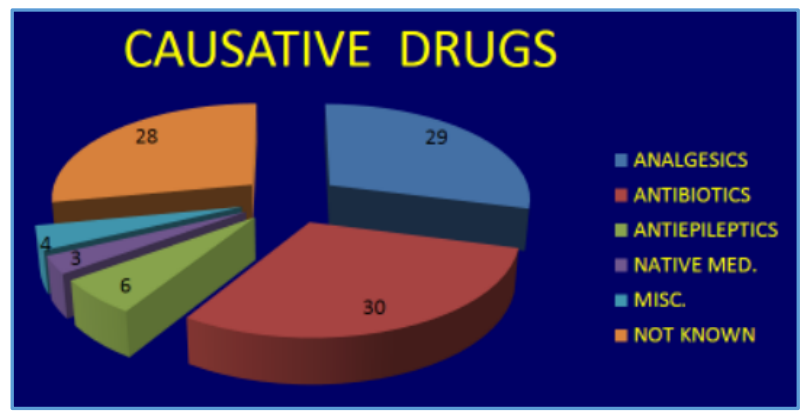

Figure 3

\begin{tabular}{|c|c|}
\hline \multicolumn{2}{|c|}{ INDICATIONS FOR USE } \\
\hline INDICATIONS & 37 \\
\hline PAIN & 18 \\
\hline RTI & 16 \\
\hline FEVER & 11 \\
\hline DIARRHOEA & 5 \\
\hline DERM & 5 \\
\hline MISCELLANEOUS & \\
\hline
\end{tabular}

Figure 4

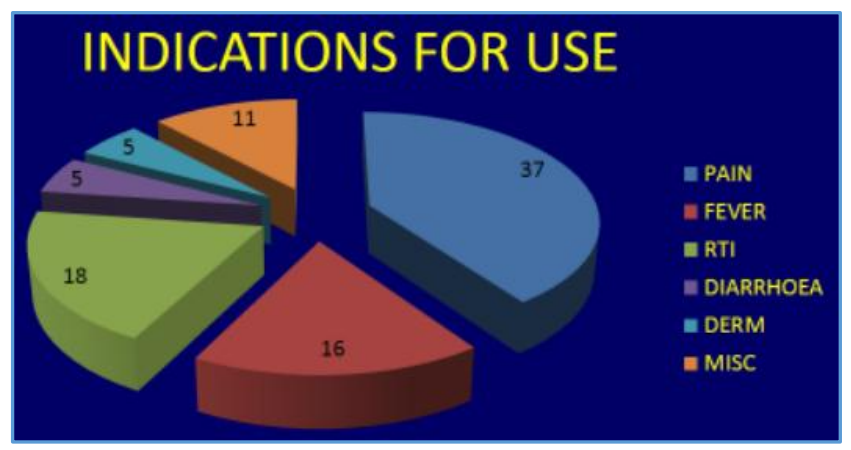

Figure 5

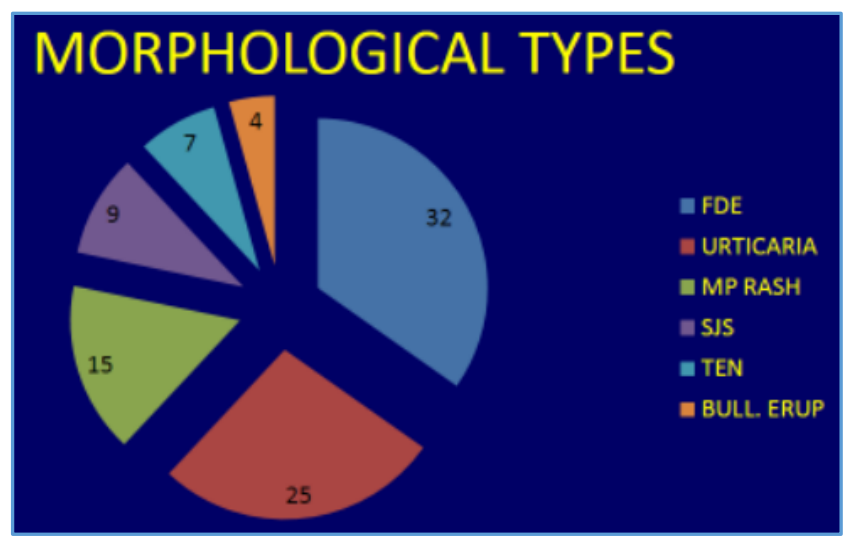

Figure 6

\section{DISCUSSION}

This study was conducted in 100 patients who attended the dermatology department during the study period. Of the 100 patients, females $(n=48)$ marginally outnumbered the males $(\mathrm{n}=45)$ as in a study conducted by Ruchika ${ }^{3}$ et al (2011) $(\mathrm{n}=47)$, but unlike similar studies conducted by Saritha ${ }^{4}$ et al (2015) who observed a male preponderance. Fixed drug eruptions was the commonest reaction pattern noticed $(n=32)$ followed by urticaria and angioedema $(n=25)$. This is in accordance with similar studies conducted by Rohini Sharma ${ }^{5}$ et al (2015) who also found fixed drug eruption to be the most common morphological patterns. But this is against a study by Punit Kumar Singh6 et al (2015) who observed that morbilliform rash to be the most common pattern. Antibiotics were the most commonly incriminated drugs followed by analgesics, which is similar to studies conducted by Ghosh ${ }^{7}$ et al (2006) and Shamna ${ }^{8}$ et al (2014). 
But similar studies done by Mithali Dua ${ }^{9}$ et al and Sudha Rani 10 et al showed that anti-epileptics were the most common causative drugs. However, Faiza ${ }^{11}$ et al showed NSAIDs to be the commonly incriminated drugs. Many of the patients were unable to name the exact drug, but pain was the most common indication $(n=37)$, for which the causative drug was used followed by respiratory infection $(n=18)$.

\section{CONCLUSION}

Females were more commonly affected. The common age group involved was 21 - 40 yrs. Antibiotics were the common offending drugs, in which cotrimoxazole was the frequently implicated agent. The commonest clinical presentation was FDE. The clinical pattern of the cutaneous adverse drug reactions is varied in this locality, the knowledge of which is essential for the clinicians.

\section{REFERENCES}

[1] Edwards RI, Aronson JK. Adverse drug reactions: definitions, diagnosis, and management. Lancet 2000;356(9237):1255-9.

[2] Ramesh M, Pandit J, Parthasarathi G. Adverse drug reactions in a south Indian hospital--their severity and cost involved. Pharmacoepidemiol Drug Saf 2003;12(8):687-92.

[3] Nandha R, Gupta A, Hashmi A. Cutaneous adverse drug reactions in a tertiary care teaching hospital: a North Indian perspective. Int J Appl Basic Med Res 2011;1(1):50-3.
[4] Sasidharanpillai S, Riyaz N, Khader A, et al. Severe cutaneous adverse drug reactions: a clinicoepidemiological study. Indian J Dermatol 2015;60(1):102.

[5] Sharma R, Dogra D, Dogra N. A study of cutaneous adverse drug reactions at a tertiary center in Jammu, India. Indian Dermatol Online J 2015;6(3):168-71.

[6] Singh PK, Kumar MK, Kumar D, et al. Morphological pattern of cutaneous adverse drug reactions due to antiepileptic drugs in eastern India. J Clin Diagn Res 2015;9(1):WC01-3.

[7] Ghosh S, Acharya LD, Rao PGM. Study and evaluation of the various cutaneous adverse drug reactions in Kasturba hospital, Manipal. Indian J Pharma Sci 2006;68(2):212-5.

[8] Shamna M, Dilip C, Ajmal M, et al. A prospective study on adverse drug reactions of antibiotics in a tertiary care hospital. Saudi Pharm J 2014;22(4):303-8.

[9] Dua M, Dua S, Gehlot A, et al. An observational study of drug induced cutaneous reactions used in various group of patients. Sch Acad J Pharm 2016;5(3):76-82.

[10] Sudha Rani C, Udayakumar B, Geetakiran A. Adverse cutaneous drug reactions to anticonvulsants - a study at a tertiary care center in Telangana. IOSR Journal of Dental and Medical Sciences (IOSR-JDMS) 2016;15(2):11-5.

[11] Al-Raaie F, Banodkar DD. Epidemiological study of cutaneous adverse drug reactions in Oman. Oman Med J 2008;23(1):21-7. 